\title{
The zipper mechanism in phagocytosis: energetic requirements and variability in phagocytic cup shape
}

\author{
Sylvain Tollis ${ }^{1,2}$, Anna E Dart ${ }^{2,3}$, George Tzircotis ${ }^{2,3}$, Robert G Endres ${ }^{1,2^{*}}$
}

\begin{abstract}
Background: Phagocytosis is the fundamental cellular process by which eukaryotic cells bind and engulf particles by their cell membrane. Particle engulfment involves particle recognition by cell-surface receptors, signaling and remodeling of the actin cytoskeleton to guide the membrane around the particle in a zipper-like fashion. Despite the signaling complexity, phagocytosis also depends strongly on biophysical parameters, such as particle shape, and the need for actin-driven force generation remains poorly understood.

Results: Here, we propose a novel, three-dimensional and stochastic biophysical model of phagocytosis, and study the engulfment of particles of various sizes and shapes, including spiral and rod-shaped particles reminiscent of bacteria. Highly curved shapes are not taken up, in line with recent experimental results. Furthermore, we surprisingly find that even without actin-driven force generation, engulfment proceeds in a large regime of parameter values, albeit more slowly and with highly variable phagocytic cups. We experimentally confirm these predictions using fibroblasts, transfected with immunoreceptor FcyRlla for engulfment of immunoglobulin G-opsonized particles. Specifically, we compare the wild-type receptor with a mutant receptor, unable to signal to the actin cytoskeleton. Based on the reconstruction of phagocytic cups from imaging data, we indeed show that cells are able to engulf small particles even without support from biological actin-driven processes.

Conclusions: This suggests that biochemical pathways render the evolutionary ancient process of phagocytic highly robust, allowing cells to engulf even very large particles. The particle-shape dependence of phagocytosis makes a systematic investigation of host-pathogen interactions and an efficient design of a vehicle for drug delivery possible.
\end{abstract}

\section{Background}

Phagocytosis is the ancient, evolutionarily conserved process by which eukaryotic cells bind, engulf, and destroy particles and cells larger than $0.5 \mu \mathrm{m}$ in diameter [1-3]. The importance of phagocytosis is derived from its two main functions: (1) a feeding mechanism in single-cell organisms [4], and (2) the clearance of pathogens, apoptotic and senescent cells from our body by immune cells $[5,6]$. As part of our immune defense, phagocytosis is mainly performed by professional phagocytes, including macrophages, neutrophils, and dendritic cells. Initiation of phagocytosis occurs with recognition

\footnotetext{
* Correspondence: r.endres@imperial.ac.uk

'Division of Molecular Biosciences, South Kensington Campus, Imperial College London, SW72AZ London, UK

Full list of author information is available at the end of the article
}

of the target particle either directly or via an opsonising molecule. For instance the Fc portion of immunoglobulin $\mathrm{G}$ ( $\operatorname{IgG}$ ) is recognized by the cell-surface receptor Fc $\gamma$ RIIa $[7,8]$. Ligand-receptor binding triggers intracellular signaling $[3,8,9]$, resulting in remodeling of the actin cytoskeleton $[10,11]$ and coherent growth of cell membrane around the particle to form the phagocytic cup $[1,2]$. Eventually, the leading edge of the growing cup closes, and a membrane vesicle enclosing the particle (phagosome) moves inside the cell. Subsequently, the phagosome fuses with vesicles containing enzymes $[12,13]$, acids [14], and oxygen radicals [15,16] to destroy the particle.

The biochemical pathways involved in phagocytosis are complex. Dozens of cell-surface receptors contribute to the recognition of a large variety of ligand molecules and

\section{C) Biomed Central}


subsequent particle engulfment $[3,8,17]$. The Fc $\gamma$ receptor $(\mathrm{F} c \gamma \mathrm{R})[18]$ and complement receptor 3 (CR3) of the integrin receptor family [19] are the most widely studied and understood receptors involved in phagocytosis. Fc $\gamma \mathrm{R}$-mediated phagocytosis proceeds through membrane protrusions and leads to thin cups [20,21], whereas in CR3-mediated phagocytosis, particles appear to sink into the cell $[22,23]$. Spreading of the cell membrane over the particle involves actin-driven cell-shape changes similar to the processes involved in cell migration and adhesion [7,24-27]. Specifically for Fc $\gamma$ R, binding to an IgG-opsonized particle results in receptor clustering and recruitment of small GTPases of the Rho family, which, via proteins of the WASP family, activate the Arp $2 / 3$ complex $[1,3]$. The latter promotes branching of actin filaments, leading to an increase in the number of uncapped ends and to an isotropic growth of the actin network $[8,28]$. Additionally, the phagocytic cup has been shown to be enriched in gelsolin [29-31], coronin [4], and other regulators of actin polymerization. All in all, this complex signaling pathway involves 100-1000 different types of molecules [3,32], rendering mathematical modeling at the molecular level impossible.

Despite the huge biochemical complexity, the engulfment process shows a strong dependence on simple biophysical parameters. First, it relies on the availability of extra membrane at the phagocytic cup [33,34], provided by delivery of membrane vesicles [35] or unwrinkling of membrane folds $[36,37]$. Second, completion of phagocytic uptake depends on the shape of the particle and, interestingly, on the initial orientation of the particle on the cell surface $[20,38]$. For instance, experiments demonstrate that elongated spheroid polystyrene particles coated with IgG are more efficiently engulfed when presented to the phagocyte with their tip first. Third, a recent study by one of the authors demonstrates that the biophysical requirements for phagocytosis lead to either complete phagocytosis or stalled cups due to the presence of a mechanical bottleneck [39]. Interestingly, the same study shows that engulfment appears to even proceed in cells treated with (modest amounts of) cytochalasin $\mathrm{D}$, an inhibitor of actin polymerization, indicating that biochemical pathways may not always be necessary for this initial stage of phagocytosis.

The mechanism of phagocytosis is only partially understood, with key insights provided more than three decades ago. In the 1970's, Griffin and his collaborators $[40,41]$ demonstrated that incomplete coating of particles with ligand results in only partial uptake. This indicated that phagocytic uptake occurs via successive zipper-like ligand-receptor binding (Figure 1A), and not by an all-or-nothing mechanism triggered at the onset of phagocytosis. The zipper mechanism is the underlying assumption in a number of recent modeling works in phagocytosis [39,42] and endocytosis [43-45], mainly addressing the influence of the cell-membrane tension and ligand-receptor bond density on engulfment. Despite the general acceptance of the zipper mechanism, many of its biophysical requirements are insufficiently understood. Questions, so far unanswered, include what the energetic requirements of the zipper mechanism are, specifically what role actin polymerization plays in its progression during phagocytosis, and also whether the zipper mechanism can explain the particle-shape dependence of phagocytosis. Previous models were unable to fully address the particle-shape dependence, as they assume rotational symmetry around the axis connecting cell and particle. Additionally, large particle-to-particle variation in cup growth [39] and cell-to-cell variation in the related process of endocytosis [46] point towards the importance of stochasticity during the uptake, not captured in previous deterministic approaches.

Recent experiments provide new insights into the biophysical mechanism for driving the membrane around the particle, suggesting a ratchet-type mechanism. Once started, phagocytosis progresses unidirectionally and irreversibly [37]. This irreversible membrane progression is further supported by the loss of lipid and protein mobility at the phagocytic cup, observed using fluorescence recovery after photobleaching (FRAP) [47]. While several models proposed mechanisms of force generation by actin polymerization (see [48] and references therein), recent experiments based on fluorescent speckle microscopy demonstrate that actin does not directly push the membrane outwards. Instead, by filling gaps provided by membrane fluctuations (or other types of membrane movement), actin polymerization prevents the membrane from moving backwards like a ratchet [42]. The relevance of such Brownian ratchets in biology has previously been emphasized $[49,50]$. The question is if a ratchet mechanism, together with energetic restrictions in membrane bending and stretching, can naturally lead to phagocytic uptake and account for the shapedependence of phagocytosis.

In this work, we propose a ratchet-like biophysical model for the zipper mechanism. This model differs from previous works in that it is, to our knowledge, the first fully three-dimensional stochastic model of phagocytic engulfment. Specifically, thermal membrane fluctuations, assumed to play a major role in our model, provide the energy source to locally deform the membrane and to build further ligand-receptor bonds for zippering the membrane around the particle. Actin polymerization makes ligand-receptor bonds effectively irreversible, i.e. reinforced and stabilized for a significant amount of time. To investigate the role of actin, we compare cup progression for the regular active zipper with a passive zipper model in which ligand-receptor 


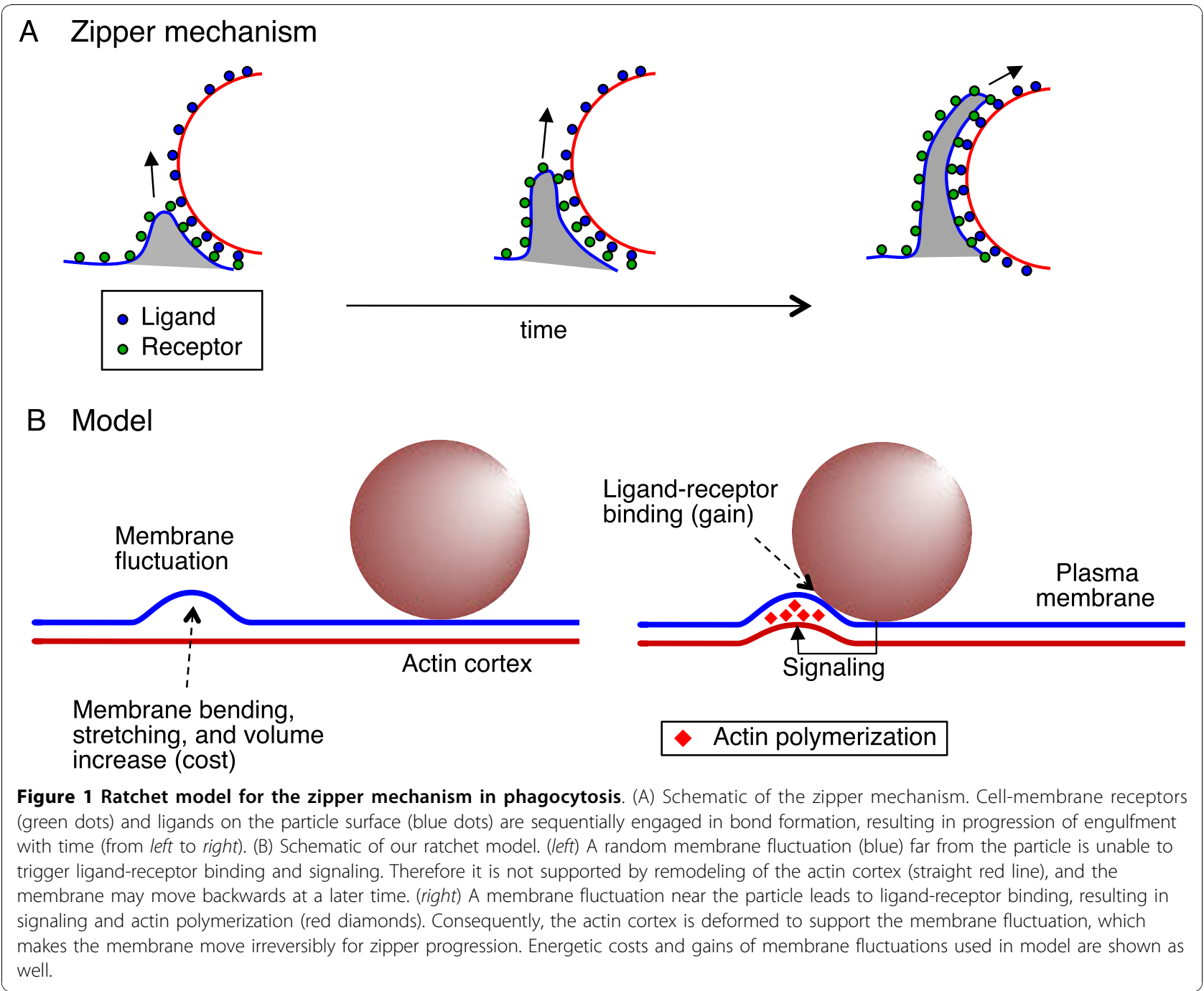

binding remains specific and strong but reversible due to the absence of actin polymerization.

Interestingly, we find that the passive zipper also leads to engulfment of small particles, rendering phagocytosis highly robust. However, such passive engulfment is generally slower and produces much more variable phagocytic cups than the active zipper. Furthermore, our computer simulations lead to successful phagocytic engulfment in a broad range of parameters values, including different particle sizes. For non-spherical particles, completion of engulfment depends strongly on particle shape and orientation. Our model further predicts that cup shape invariably depends on membrane biophysical parameters, in particular surface tension and cell-volume constraint.

To test the predicted difference between the active and passive zippers, we experimentally implement the two different types of zippers using COS-7 fibroblasts which, after transfection with GFP-tagged Fc $\gamma$ receptor, phagocytoze IgG-coated polystyrene particles. Specifically, we performed phagocytic assays under three different conditions: (1) cells expressing wild-type Fc $\gamma \mathrm{R}$ for the active zipper (WT-Fc $\gamma \mathrm{R}),(2)$ cells expressing a signaling-dead mutant receptor (Y282F/Y298F-Fc $\gamma$ R), which specifically binds IgG ligand but is unable to signal to the actin cytoskeleton $[39,51,52]$, and (3) cells expressing WT-Fc $\gamma \mathrm{R}$ and treated with cytochalasin D (WT-Fc $\gamma \mathrm{R}+\mathrm{CytoD}$ ). The last two conditions represent two versions of the passive zipper due to the absence of actin polymerization in phagocytic cups. To compare with our model, we systematically analyze confocal microscopy images, and quantitatively estimate cup variability for the three different conditions using small (1.5 $\mu \mathrm{m}$ radius) and large (3 $\mu \mathrm{m}$ radius) particles. Consistently with our simulations, phagocytic cups develop more slowly and are significantly more variable in the absence of actin polymerization. Our results provide new insights into the robustness of phagocytosis, as well 
as the role of bacterial cell shape in host-pathogen interactions.

\section{Results and Discussion}

Ratchet model for the zipper mechanism

Our model is based on the following experimental observations. Engulfment of quasi-spherical particles by neutrophils progresses continuously without significant pause or reversal, indicating that ligand-receptor binding is essentially irreversible [37]. This irreversibility is further supported by FRAP and single-molecule experiments, which show that lipids and proteins in phagocytic cups, as well as ligand-bound Fc-receptors are immobilized in an actin-dependent fashion $[47,53]$. Additional support for the notion of irreversible uptake was recently determined in a related context [54]. Fluorescent speckle microscopy of actin flow and image analysis during cell migration show that the membrane at the leading edge protrudes first, followed by actin polymerization to fill the gap between the membrane and the actin cortex. Such actin polymerization is mainly restricted to the leading edge due to signaling by receptors and/or localization of small GTPases of the Rho family [8]. The role of actin polymerization in phagocytosis is hence to stabilize ligand-receptor bonds and to rectify membrane movements in a ratchet-like fashion, leading to unidirectional movement of the leading edge of the engulfing cell.

Figure $1 \mathrm{~A}$ introduces the general concept of the zipper mechanism in phagocytosis, and Figure 1B summarizes our ratchet model for this mechanism. The cell membrane and the actin cortex are described by a Helfrich-type energy function [55], including contributions from ligand-receptor binding, membrane bending and stretching, as well as a cell-volume constraint. Chosen membrane parameters effectively describe the cell plasma membrane with its underlying actin cortex. The model was implemented using finite-temperature Monte Carlo simulations of the discretized cell membrane (see Methods for details). Briefly, the algorithm proposes random, thermally generated membrane fluctuations (trial moves), which are either accepted or rejected depending on the change in total energy during the move. When a random membrane fluctuation brings the cell membrane in contact with the particle, this fluctuation is likely accepted due to energetically favorable ligand-receptor binding. Once accepted, this fluctuation is made irreversible as a result of signaling and actin polymerization. In contrast, a membrane fluctuation far away from the particle is less likely to be accepted. Even if accepted, the fluctuation is not made irreversible and hence may retract at a later time (see Additional file 1, Figure S1). Hence, in our model the actin network only supports membrane fluctuations which lead to progression of the engulfing zipper as a result of signaling.

\section{Dependence of phagocytic cup shape on membrane biophysical parameters}

Using our model for the zipper mechanism, we have successfully simulated phagocytic engulfment in a broad range of parameter values (see Figure 2, and movie Additional file 2). Figure 2A shows two different characteristic cup shapes we obtained. Low surface tension (i.e. low energy cost for stretching the membrane and underlying actin cortex), and tight cell-volume constraint (i.e. high energy cost for increasing the cell volume), lead to a thin phagocytic cup since a thin cup requires extra membrane but little extra volume. In contrast, weak volume constraint and/or high surface tension produce a broad cup. Based on the parameters explored, we chose intermediate values for both surface tension and cell-volume constraint as our Standard Parameters (SP) for the remainder of our simulations in order to produce realistic cup shapes (see Methods for details). Figure 2B shows that most parameter values can be changed independently by at least one order of magnitude, without negatively affecting engulfment completion. Note that changing simultaneously several parameters may affect engulfment more drastically. Our simulations also show that cup shape depends on the kinetics of engulfment, determined by membrane fluctuations and therefore temperature (see Additional file 1, Figure S2). Additionally, preventing thermal fluctuations (by setting the temperature to zero Kelvin) during a simulation stops cup progression. This indicates that in our model membrane fluctuations are indeed required to bring receptors in close contact with ligand molecules on the particle, emphasizing their important role in the ratchet mechanism.

\section{Active versus passive uptake and the role of actin}

Although phagocytosis generally involves active processes such as actin polymerization in the cup (active zipper) [11], recent reports indicate that phagocytosis may still work in an actin-independent manner. Indeed, phagocytic uptake was observed despite treating phagocytes with (modest amounts of) cytochalasin D [39]. Hence, ligandreceptor binding may be sufficient in guiding the cell membrane around the particle under certain conditions (passive zipper). To investigate the energetic requirements of the zipper mechanism, we implemented simulations of the passive zipper. In these simulations, ligandreceptor bonds are not stabilized by actin polymerization and can unbind at later times, i.e. remain reversible. Hence, engulfment may still progress if the energetic cost of stretching and deforming the membrane is offset by the ligand-receptor binding energy in the presence of thermal membrane fluctuations. 


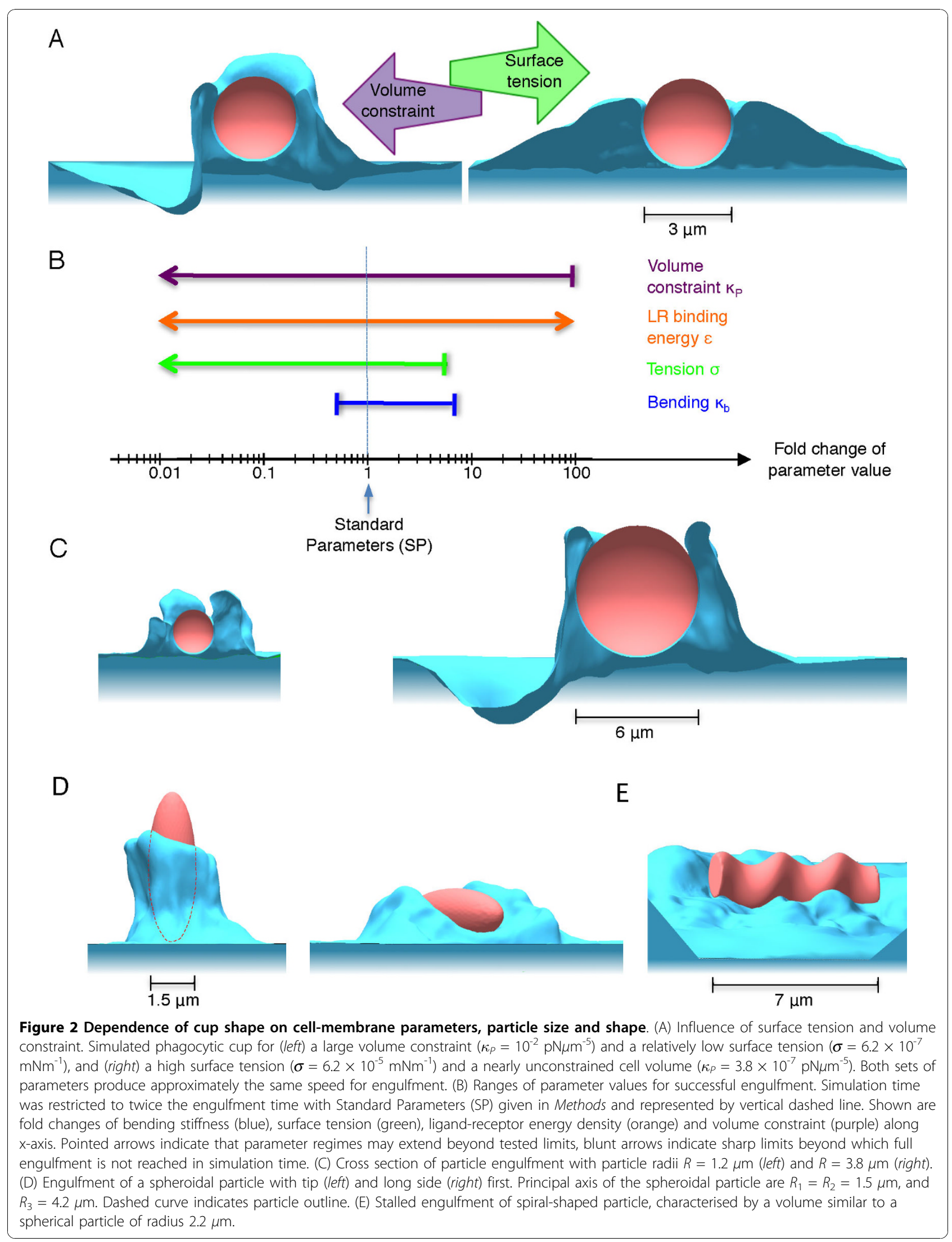


Figure 3 (left) shows that engulfment of small $(1.5 \mu \mathrm{m}$ radius) particles by the passive zipper leads to more variable phagocytic cup shapes than engulfment by the active zipper. For the active zipper, random membrane fluctuations are rectified by irreversible ligand-receptor binding due to actin polymerization. This leads to uniform progression of the cell membrane all around the particle at approximately the same speed (Figure 3A). In contrast, engulfment by the passive zipper occurs through binding of large membrane ruffles which eventually enclose the particle (Figure $3 \mathrm{C}$ ). The variability of the phagocytic cup may be a measure of the respective contributions of active and passive processes in engulfment progression.

Figure 3 (right) compares time courses of the membrane energy and progression of uptake for the active and passive zippers. We found that in both cases, membrane energy decreases rapidly at the very beginning of the uptake process due to energetically favorable ligand-receptor binding without large, energetically unfavorable deformations of the cell membrane. After this short initial period, the total energy increases with simulation time. This increase is much more pronounced for the active zipper, which stabilizes energetically unfavorable random membrane fluctuations by actin polymerization. In contrast, for the passive zipper such high-energy membrane deformation may not last over time. The slower increase in energy for the passive zipper correlates with a slower engulfment. For the simulations shown, engulfment for the active zipper is approximately twice to three times as fast as for the passive zipper, although the latter eventually engulfs the particle. However, the difference between active and passive engulfment depends on biophysical parameters,
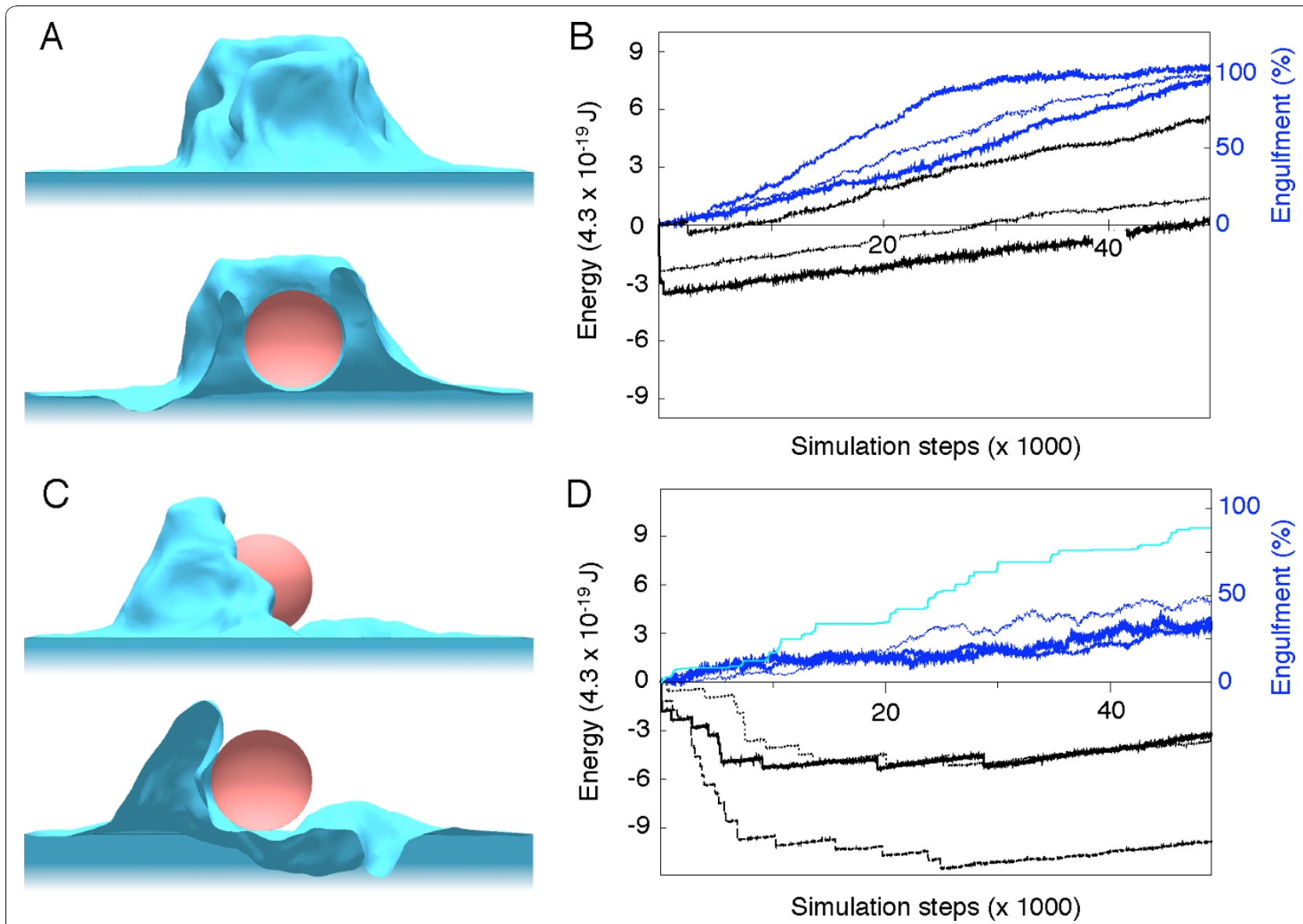

Figure 3 Engulfment simulations of active and passive zippers. (A) Side view (top) and cross section (bottom) of a phagocytic cup obtained for the active zipper. (B) Corresponding time courses of the membrane energy (thick solid, medium dashed and thin dotted black lines) and percentage of engulfment, defined by the average membrane height around the particle (blue solid, blue dashed, blue dotted lines) for three repeats of the stochastic simulation. (C) Side view (top) and cross section (bottom) of the phagocytic cup obtained for the passive zipper (same overall simulation time). (D) Corresponding time courses of the membrane energy (thick solid, medium dashed and thin dotted black lines) and engulfment (blue solid, blue dashed, blue dotted lines) for three repeats of the simulation. Dashed light blue line indicates corresponding maximal membrane height for one of the simulations (in percentage of the particle diameter). Small particles with $1.5 \mu$ m radius were used. 
and may be reduced for particular choices of the parameters values, e.g. lower surface tension and/or stronger ligand-receptor binding.

\section{Particle size matters for passive, not for active zipper}

Experiments show that phagocytosis is relatively insensitive to particle size [42]. Using our model for the active zipper, we simulated engulfment of spherical particles with different radii ranging from 1.2 to $3.8 \mu \mathrm{m}$. Figure $2 \mathrm{C}$ shows that engulfment progresses normally for small and large particles. Hence the active zipper mechanism is sufficiently robust to allow engulfment of differently sized particles using the same set of biophysical parameters, although engulfment of large particles requires more time. Noticeably, large particles (in general, with radius larger than $2.5 \mu \mathrm{m}$ ) were taken up via more regular phagocytic cups than small particles (with radius $1.5 \mu \mathrm{m}$ or smaller), indicating that active processes may be required for engulfment of large particles. To confirm this observation we have simulated engulfment of large $3 \mu \mathrm{m}$-radius particles by both the active and the passive zipper, shown in Additional file 1, Figure S5. While the active zipper resulted in complete uptake of the particle, the passive zipper only engulfed a few percent of the particle's surface area. Thus the difference in phagocytic efficiency between the two zipper types was exacerbated for large particles, reflecting the importance of actin polymerization for engulfment of large particles.

\section{Experimental test of model predictions}

To test our model predictions and to specifically compare active with passive engulfment for small and large particles, we transfected COS-7 cells with either wildtype Fc $\gamma \mathrm{R}$ (WT-Fc $\gamma \mathrm{R}$ ) or a signaling-dead mutant receptor (Y282F/Y298F-Fc $\gamma \mathrm{R}$ ). Cells expressing the wild-type receptor are expected to perform active engulfment, whereas cells expressing the signaling-dead mutant receptor are expected to perform passive engulfment. As a control, passive engulfment is additionally implemented by treating cells expressing WT-Fc $\gamma \mathrm{R}$ with $0.2 \mu \mathrm{M}$ of cytochalasin D (WT-Fc $\gamma R+C y t o D)$, which prevents actin polymerization (see Methods). Synchronized phagocytosis assays using small (1.5 $\mu \mathrm{m}$ radius) and large (3 $\mu \mathrm{m}$ radius) IgG-opsonized polystyrene particles were carried out, and, after fixation, receptor localization in phagocytic cups was visualized by fluorescence confocal microscopy. Cells were imaged at different time points during phagocytosis, and at each time point, three to eight imaged cells were each engulfing simultaneously between four and twenty particles (Figure 4A). Consequently, for each condition we analyzed at least seventy particles.

To test whether passive engulfment leads to more variable cups than active engulfment, we developed an image-analysis method illustrated in Figure 4B-F. The cup shape varibility was quantified by the standard deviation of the distribution of cell-membrane (Fc $\gamma \mathrm{R}-$ GFP fluorescence) height around the particle, divided by the square root of the average membrane height. The unit of membrane height is given by the distance $(0.4 \mu \mathrm{m})$ between consecutive confocal image planes (see Methods). Figure 5A shows that for small particles engulfed between 20 and $40 \%$ of their surfaces, cup variability increases from cells transfected with wild-type receptor to cells transfected with signaling-dead mutant receptor to WT-Fc $\gamma+C y t o D$ cells. The lowest variability, found for cells expressing wild-type receptor, is statistically significant against both passive zipper types (Student's t-test, p-value $<0.001)$. This result is consistent with model predictions: Figure 5A, inset shows the cup variability from simulations, revealing that the active zipper leads to significantly less variable cups. In contrast, for the ranges of engulfment between 40 and $60 \%$ (Figure 5B) and between 60 and 100\% (see Additional file 1, Figure S7) we observed no noticeable difference in cup variability between the three experimental conditions, while our model consistently predicts more variable cups for the passive zipper (Figure 5B, inset). This discrepancy may indicate that active processes such as contraction by myosin motor proteins become important at later stages of engulfment, limiting our model's full validity to the early events in phagocytosis (see Conclusion section).

To confirm that our results are independent of the specifics of the analysis method used, we also analyzed phagocytic cups with an alternative, albeit less accurate, method (see Additional file 1, Figure S9). This method consists of determining the distribution of Fc $\gamma$ R-GFP fluorescence intensity around the particle at its equator plane, restricting the analysis to approximately half taken up particles (30-70\%). The standard deviation of this distribution provides an alternative measure of the cup variability. We arrived at the same conclusion, confirming our result of the difference in cup variability (see Additional file 1, Figure S10). Finally, note that temperature-induced synchronization is imperfect and may lead to variability in cup growth [39]. However, our measures of the variability in cup shape are independent of such an effect since we include all time points together in the analysis (except for plots showing the time dependence of engulfment).

Our experiments further show that cup shape ranges from regular to variable for all three experimental conditions, but that the frequency of different cup shapes depends on the condition. Figure $5 \mathrm{C}$ plots the repartition of phagocytic cups for different conditions into both regular and variable cups. Note that a cup was identified as regular if its variability was below the 


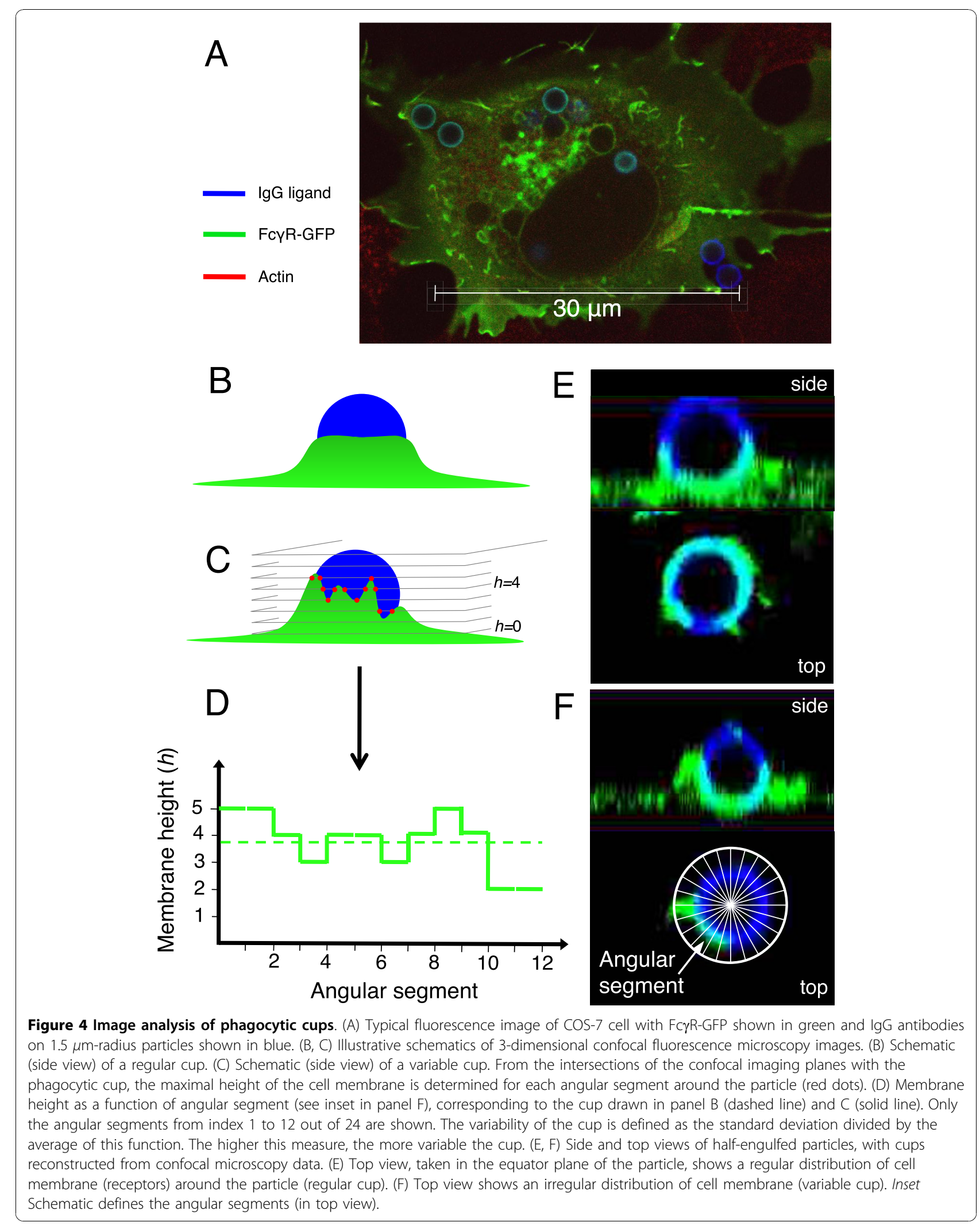




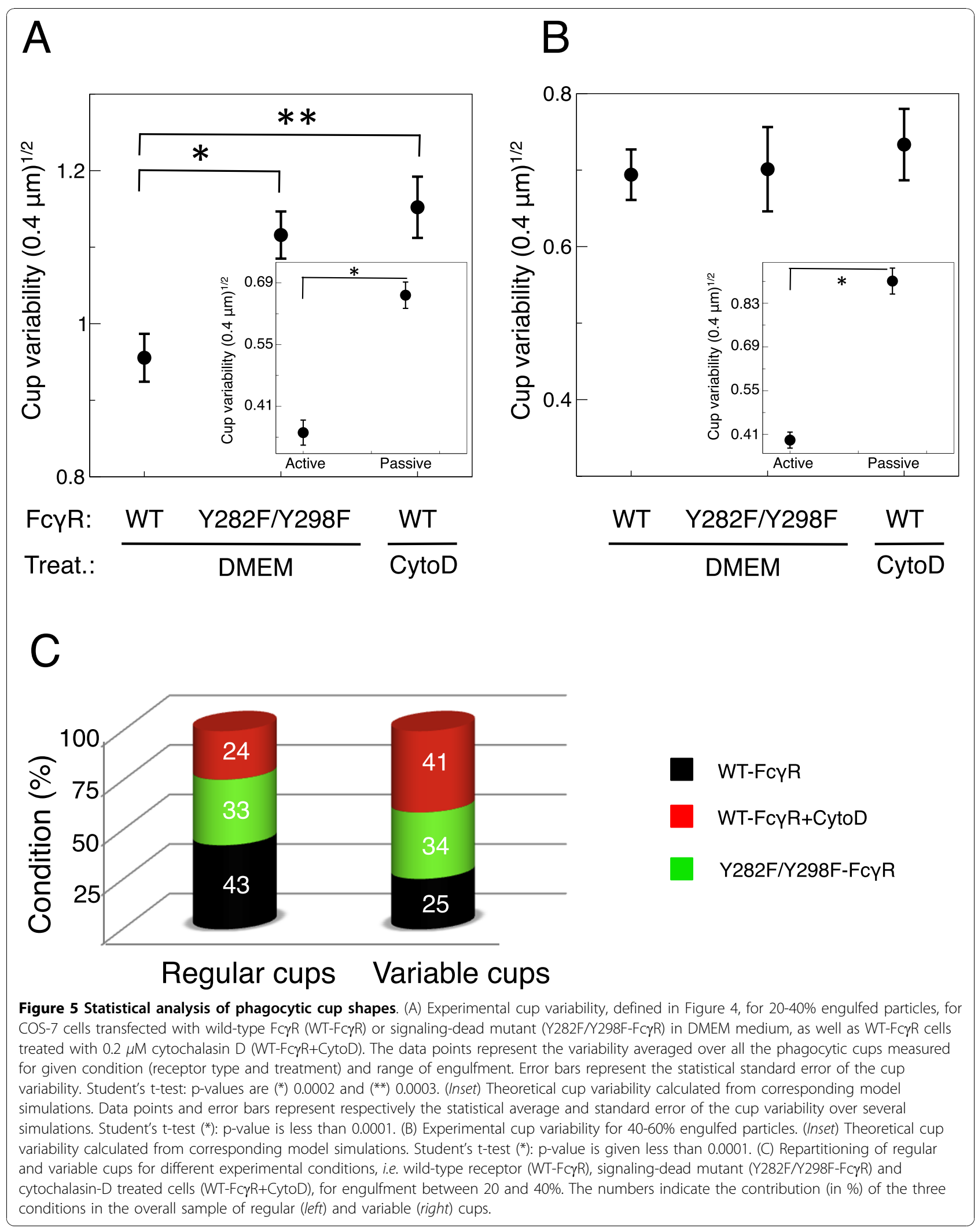


variability averaged over all experimental conditions. In contrast, a cup was identified as variable if its variability was above the overall average. This plot shows that in our experiments a regular cup is most likely produced by a cell expressing wild-type receptor, whereas a variable cup is most likely to be produced by a cytochalasin-D treated cell. Hence, the cup shape has universal features independent of biochemical details. Examples of a regular and a variable cup are provided in Figures $4 \mathrm{E}$ and $4 \mathrm{~F}$, respectively. Both cups were taken from a cytochalasin-D treated cell, confirming that a regular cup can occur under any of our experimental conditions.

Our model also predicts that uptake by the active zipper is significantly faster than with the passive zipper (see Figures 3B and 3D). We experimentally tested this prediction by determining the percentage of engulfed surface area for each particle for different time points after initiation of phagocytosis, and comparing this result with our simulations, in which simulation time was matched to actual time. Figure 6A shows that cells transfected with the wild-type receptor (active zipper) engulf significantly faster (three to four times) than cells under the other two conditions (passive zippers). This result is in quantitative accordance with our model predictions (Figure 6B). Furthermore, we determined the time dependence of phagocytic uptake for large particles. The active zipper, although slower for large than for small particles, still engulfs regularly, both in experiments (Figure 6C) and simulations (Figure 6D). Note that predicted and measured time courses are in very good agreement without rescaling the time axis of the large-particle simulation. Furthermore, Figures $6 \mathrm{C}$ and 6D demonstrate the inability of the passive zipper to take up large particles, in both experiments and simulations. After more than 10 minutes, the average engulfed surface area remains below $20 \%$.

Note that for the time points measured, the average uptake does not exceed 50\%, even for WT Fc $\gamma \mathrm{R}$. This is caused by the fact that some particles are not engulfed irrespective of the condition [39] (see Additional file 1, Figure S6), reducing the average percentage of engulfment. The proportion of almost completely engulfed particles (with engulfed surface area larger than 70\%) beyond 6 minutes is represented in the inset of Figure $6 \mathrm{~A}$, showing that completion of engulfment is possible even for cells without actin polymerization. Note that long phagocytic assays (12, 14, and 45 minutes) were performed for cytochalasin-D treated cells only, explaining why the difference in complete engulfment with cells expressing the wild-type receptor is smaller than one may expect.

From these results, we conclude that functional actin polymerization is required for fast and regular engulfment in phagocytosis. Nevertheless, in line with our model predictions, cells showing deficient actin polymerization at cups are still able to uptake small particles, although more slowly and with more variable cups.

\section{Active zipper reproduces particle-shape dependence of phagocytosis}

Previously published experiments show that phagocytosis depends strongly on particle shape. In particular, elongated particles (similar to rod-shaped bacteria) are only taken up when presented to the phagocyte with their tip first $[20,38]$. To test the particle-shape dependence of phagocytosis we conducted simulations of the active zipper using particles of different shapes while varying the initial orientation of the particle on the cell surface. Figure 2D shows the uptake of a prolate spheroid for two different orientations on the cell membrane after the same elapsed simulation time. In accordance with experimental observations [20,38], uptake is more advanced for the spheroid particle engulfed with its tip first (about $80 \%$ engulfed surface area) than for the particle attached along its major axis (about 50\% engulfed in the same amount of time). This suggests a strong inhibitory effect of high local curvature on uptake. In our model this is readily attributed to the energetic cost of bending the membrane around the two highly curved ends of an elongated particle placed horizontally on the cell membrane. In line with this explanation and experiments [38], the spiral-shaped particle in Figure 2E is not engulfed after a time duration sufficient for the engulfment of large spherical particle of twice its volume. Hence, our simulations demonstrate that particle shape and orientation are indeed important biophysical parameters for phagocytosis.

\section{Conclusion}

In this work, we studied the biophysical requirements of the zipper mechanism, in particular the role of receptorinduced actin polymerization, and the effect of particle shape on uptake. In our model, the underlying biophysical mechanism of the zipper is an actin-driven thermal ratchet, which renders random membrane fluctuations irreversible close to the particle (Figure 1). This mechanism is supported by several recent experiments $[37,47,54]$. Previously, such Brownian ratchet models were successfully applied to explain force generation by actin polymerization and motility of the pathogen Listeria in hosts cells [49]. Our fully stochastic simulations can address for the first time the variability in particle uptake, recently noticed in phagocytic cup growth [39] and completion of endocytosis [46]. Implementation of our model in simulations led indeed to phagocytic engulfment for a broad range of values of membrane parameters (Figure 2), indicating exquisit robustness of the phagocytic process. However, phagocytic cup shape 


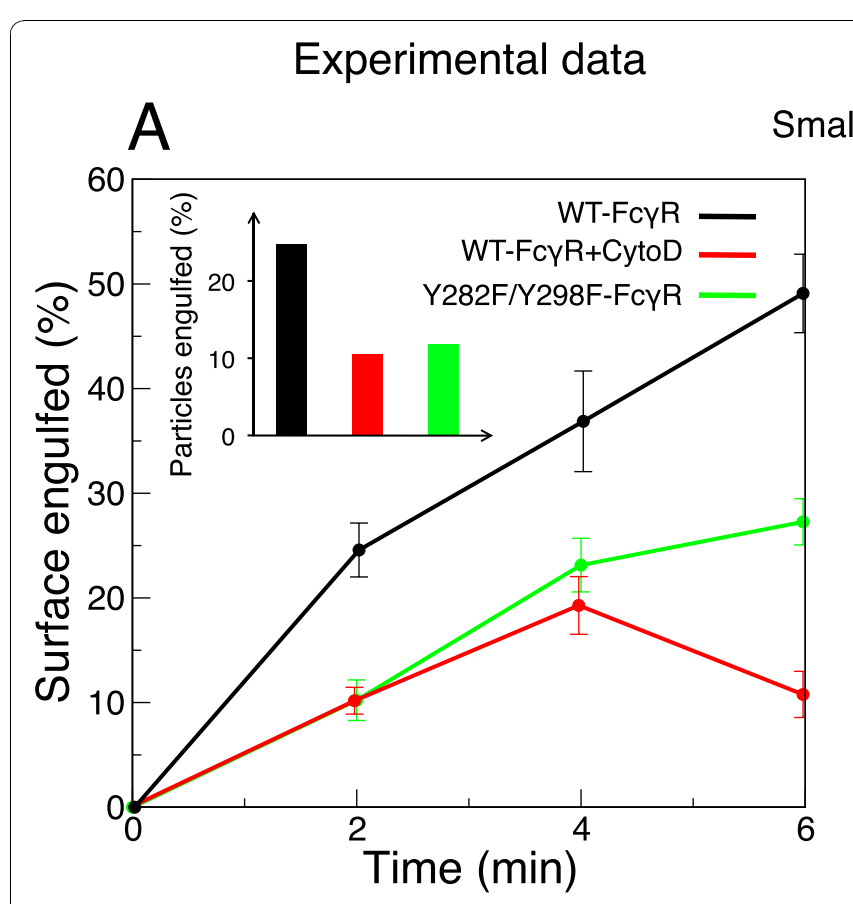

\section{Simulated data}

Small particles B
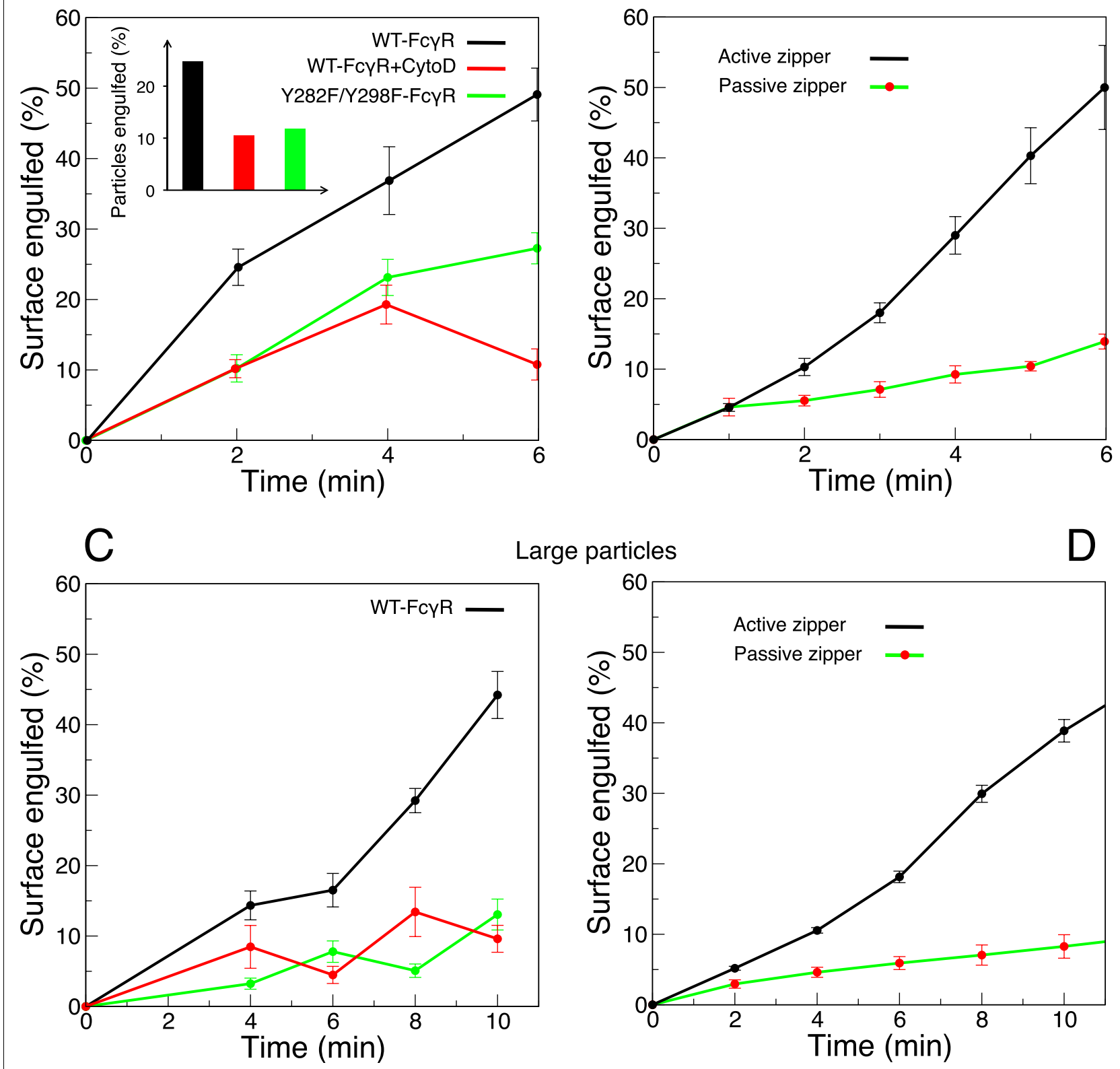

Large particles

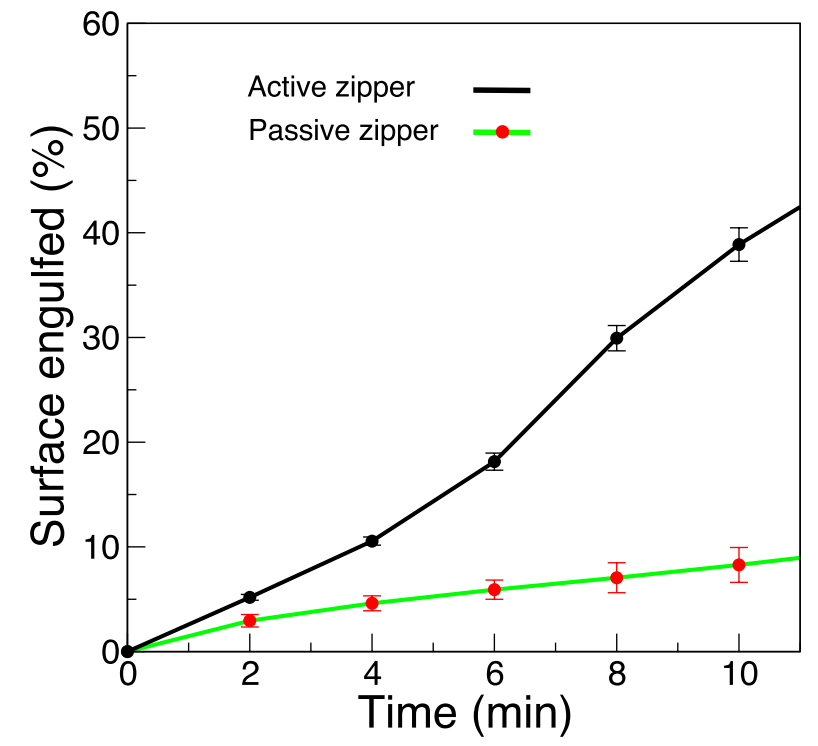

Figure 6 Progression of phagocytic engulfment with time. Experimental data for small particles with $1.5 \mu \mathrm{m}$ radius (A) and large particles with $3 \mu \mathrm{m}$ radius (C). The data points represent averages of phagocytic cups obtained at given time points for the three different experimental conditions. Error bars represent the corresponding standard errors. (A, Inset) Proportion of almost completely taken up particles (engulfed surface area larger than 70\%) after at least 6 minutes for the three conditions. (B, D) Progression of phagocytic engulfment with time in the simulations for small (B) and large (D) particles. Simulation time was converted to actual time so that $50 \%$ average engulfment of small particles by the active zipper corresponds to $6 \mathrm{~min}$. No further adjustment of time conversion was done for large-particle simulations. The data points and error bars represent respectively the statistical average and standard error of phagocytic cups size from several simulations.

depends on parameter values, specifically on the ratio between surface tension and cell-volume constraint, as well as on the kinetics of engulfment. Cells with low surface tension and/or tight volume constraint develop thin cups (Figure 2A, left), characteristic of Fc $\gamma \mathrm{R}$ mediated phagocytosis $[4,22]$. In contrast, cells with high surface tension produce broad cups (Figure 2A, right). The latter cup shape is more reminiscent of 
CR3-mediated phagocytosis, although for this type of phagocytosis particles are believed to sink into cells without protrusive cups $[22,23]$.

Using our model we were able to address the question whether the zipper mechanism requires an active driving force, such as provided by actin polymerization. For this purpose, we compared the regular active zipper with a passive version of the zipper. In the passive zipper, ligand-receptor bonds are as strong as for the active zipper (based on experimental observation [39]) but are reversible, i.e. are not supported by actin polymerization. We demonstrated that the passive zipper also leads to engulfment of small particles (of radius $1.5 \mu \mathrm{m}$ ), although cup progression is slower and more variable (see Figure $3)$. Our active zipper can also reproduce the independence of uptake on particle size, in line with experimental observations [42]. In contrast, large particles (of radius 3 $\mu \mathrm{m})$ are poorly phagocytozed by the passive zipper. We subsequently confirmed these predictions with experiments by transfecting COS-7 fibroblasts with wild-type Fc $\gamma R$ and signaling-dead mutant Y282F/Y298F Fc $\gamma$ R (see Figures 5 and 6). While the wild-type receptor represents the active zipper, the passive zipper is implemented through the use of signaling-dead mutant receptor or treatment with cytochalasin D. Both prevent actin polymerization in the cups. Our study may indicate that ancient forms of phagocytosis were driven by physical (passive) principles, and only later in evolution biochemical regulatory pathways were added for further support and robustness. Passive phagocytosis may also become important when energy sources are scarce.

Despite the robustness of phagocytosis to particle size, there appears to be a mechanical bottleneck around half-engulfment, recently observed by imaging [39] and also predicted by our model. For slight variations in some of the parameters, our simulations of the active zipper produce either complete or significantly incomplete uptake (see Additional file 1, Figure S6). Indeed, when the cup grows, deforming the membrane costs more and more energy per surface area engulfed. Beyond half-engulfment, the surface tension energy is twice as high as at the beginning of engulfment due to the membrane folding back onto itself. If this energy cannot be provided by the zipper, then cup progression stalls and the particle remains incompletely engulfed. Alternatively, the experimental data on incomplete particle uptake may be the result of particle attachment on cell-membrane areas, unable to phagocytose due to other reasons, such as unfavorable local cell-surface curvature, proximity to cell edge or nucleus, or missing proteins, lipids, and smaller molecules belonging to key signaling pathways. Further studies will be required, ideally using live-cell imaging to avoid the need for conserving the cell's internal structures by fixation [56].
Our model for the zipper mechanism can also explain the strong particle-shape dependence observed in phagocytosis. Experiments show that an elongated spheroid is rapidly engulfed if the particle attaches to the cell membrane with its tip, but not if the particle attaches along its major axis [20,38]. Furthermore, spiral-shaped particles are not phagocytozed [38]. The strong particleshape dependence of phagocytosis is likely of biological relevance. On the one hand, it may increase the rate of infection of host cells by pathogenic bacteria. Indeed, recent experiments show that Mycobacteria tuberculosis and marinum are efficiently taken up and later released for spreading of the infection with the bacteria's tip first [57]. On the other hand, the highly curved shapes of some bacteria, e.g. the spiral-shaped Helicobacter and Campylobacter species, may prevent their uptake by macrophages [38], although injection of effector proteins can also be used by pathogens to hijack the immune or host cell's phagocytic response $[58,59]$. Furthermore, the particle-shape dependence of phagocytosis may be exploited to improve drug delivery by enclosing active drugs in particles, whose shape prevents uptake and destruction by macrophages $[38,60]$.

While our biophysical model for the zipper mechanism is readily accessible for analysis and interpretation, the small number of model parameters makes a direct comparison with measured parameter values difficult. First, our membrane parameters such as surface tension and bending stiffness are an order of magnitude smaller than reported bulk membrane parameters (see Methods). This reduction is not surprising as cells regulate these parameters locally for efficient uptake [61-63]. Such regulation may include lowering of the surface tension by local membrane delivery through vesicles $[35,64,65]$ and unfolding of membrane wrinkles [36], as well as changes in the lipid and protein composition in the phagocytic cup [1]. Second, our description of ligand-receptor interaction assumes that ligand and receptor distributions are continuous and homogeneous, while experiments indicate the formation of receptor micro-clusters [66], possibly as part of lipid rafts [47]. Third, our mechanism for actin polymerization based on membrane fluctuations neglects the role of the motor proteins (myosin I and II), whose role in membrane deformations has been established $[67,68]$. Consequently, our simulations describe well the dynamics of engulfment during the first two thirds of the uptake. At later stages of uptake, experiments show that phagocytic cups close rapidly with a thin membrane protrusion $[4,69]$, while our simulations show slow cup closure. However, taking into account myosin-driven contraction is beyond the scope of the current work.

Our model may also be applicable to other biological systems in which a zipper-like mechanism is involved. 
One such example is sporulation of Bacillus subtilis during starvation. After asymmetric cell division, the larger mother cell engulfs the smaller forespore for spore maturation. Interestingly, the mother cell even engulfs the forespore when the cell wall is artificially removed. This process occurs in a fast, zipper-like fashion without known sources of energy [70]. Importantly, forespore engulfment is subject to high variation. About $60 \%$ of the cells successfully complete forespore engulfment, while $40 \%$ do not at all, similar to the observation of the mechanical bottleneck in phagocytosis. Other examples of engulfment may not be driven by a zipper mechanism. For instance, the penetration of red blood cells by the malaria Plasmodium merozoite is driven by an elaborate actin machinery of the particle (the parasite), which devotes all its resources to wrap the cell membrane around itself. In stark contrast to phagocytosis, the engulfing host cell is completely passive [71].

\section{Methods}

Theoretical techniques

\section{Cell membrane and particle models}

The cell membrane is described by a two dimensional elastic sheet $[55,72]$, which includes both its lipid bilayer and associated actin cortex. The particle is assumed to be rigid and immobile. Moreover, we account for ligand-receptor binding and include a constraint on the cell volume. Therefore, the total free energy is given by

$$
E=E_{\mathrm{m}}+E_{\mathrm{vol}}+E_{\mathrm{LR}}
$$

where

$$
E_{\mathrm{m}}=\int_{m} d^{2} \mathbf{r}\left[\frac{\kappa_{b}}{2} C^{2}(\mathbf{r})+\sigma\right]
$$

with $C^{2}(\mathbf{r})=C_{1}{ }^{2}(\mathbf{r})+C_{2}{ }^{2}(\mathbf{r})$ the square curvature obtained from the minimal $\left(C_{1}\right)$ and maximal $\left(C_{2}\right)$ curvatures at point $\mathbf{r}$. Note that the term corresponding to the product $C_{1}(\mathbf{r}) C_{2}(\mathbf{r})$ is independent of the actual shape of the membrane as long as the overall topology is conserved, and therefore is ignored (Gauss-Bonnet theorem). Bending stiffness $\kappa_{b}$ reflects the energy cost of bending, and surface tension $\sigma$ reflects the energy cost of stretching the membrane with underlying actin cortex. Furthermore, expanding or shrinking the cytosol locally costs the energy

$$
E_{\mathrm{vol}}=E_{\text {cell }}(V)-E_{\text {cell }}\left(V_{0}\right)=\kappa_{P}\left(V-V_{0}\right)^{2},
$$

where the quadratic dependence on actual volume $V$ comes from the lowest order Taylor expansion of the cell energy around local steady state volume $V_{0}$, and
$\kappa_{P}=\frac{1}{2}\left(\frac{\partial^{2} E_{\text {cell }}}{\partial V^{2}}\right)_{V=V_{0}}$. Taylor expansion is justified by the fact that our simulations and experiments use particles significantly smaller than the cell (at least 10-20 times in volume). Finally, in our model ligand-receptor binding is not described explicitly at the molecular scale, but is accounted for by a membrane-particle contact potential $V_{L R}(\mathbf{r})$, where $V_{L R}(\mathbf{r})=-V_{L R}^{0}$ if a membrane patch is within a distance $R_{0}$ of the particle and zero if further away. Specifically, the associated energy is given by

$$
E_{\mathrm{LR}}=\int_{m} d^{2} \mathbf{r} V_{\mathrm{LR}}(\mathbf{r})
$$

where the integral is performed over the cell-membrane area. Effectively, $V_{L R}^{0}$ is given by the product of the individual ligand-receptor binding energy and the density of ligand-receptor bonds, divided by the density of vertices on the model membrane (see below). The width of the square potential $R_{0}$ is chosen to be very small compared to the other length-scales of the model $R_{0}<0.1 R$ and does not influence the results.

\section{Finite-element approximation}

Simulations of phagocytic engulfment were implemented by discretizing the cell and particle surfaces using the Surface Evolver software [73]. This software is designed to perform energy minimization on flexible surfaces, and is freely available from http://www.susqu.edu/facstaff/b/brakke/evolver. The software includes a built-in programming language, which we used to implement a Monte Carlo algorithm (see below). The cell membrane is approximated by a finite number of vertices, used to create a triangular mesh. The software computes the local energy density at each vertex and sums up the energy contributions from all the surface elements to obtain the total free energy Eq. 1.

\section{Main model parameters}

Our model uses four tunable biophysical parameters. Unless otherwise specified, we have used the set of Standard Parameters (SP), chosen according to experimental measurements $[37,42,61,74]$ when possible (see Supplementary Information, section 1), but ultimately to produce realistic cup shapes (see Figure 2). This set of parameters includes: the cell membrane bending rigidity $\kappa_{b}$ and surface tension $\sigma$, respectively set to $1.3 \times 10^{-2}$ $\mathrm{pN} \mu \mathrm{m}$ and $6.2 \times 10^{-6} \mathrm{mNm}^{-1}$, i.e. slightly below the experimentally measured values since local changes in chemical composition of the cups membrane may reduce these parameters $[1,8,36,75-77]$. The third parameter is the total binding energy density $\epsilon=58.5$ 
$\mathrm{pN} \mu \mathrm{m}^{-1}$. This value was estimated from measurements of the individual Fc $\gamma$ R-IgG binding free energy $\Delta F_{L R} \approx$ $20 k_{B} T$ [78-81], the average density $d_{L R}=270-435$ $\mu \mathrm{m}^{-2}$ of IgG-Fc $\gamma R$ bonds [82], and the fact that in response to diffusion and trapping or signaling, receptors may cluster at the cup. Finally, the local constraint on cell-volume has been chosen $\kappa_{P}=2.56 \times 10^{-5}$ $\mathrm{pN} \mu \mathrm{m}^{-5}$ to allow 20 percent volume variation in line with observation $[83,84]$.

\section{Monte Carlo simulations}

The Surface Evolver was only used to obtain a triangular mesh (vertices connected by edges) of the cell membrane, and to resample the membrane as the uptake progresses. The cell-membrane evolution was implemented using finite-temperature Monte Carlo Metropolis simulations $[85,86]$. Details of the simulation can be found in the Supplementary Information, section 2. Briefly, our algorithm calculates the total energy of the initial membrane configuration, then randomly selects a point to be the center of a membrane fluctuation, and a random direction and lateral extension of the fluctuation. Subsequently, the energy of the new membrane configuration is calculated, and compared to the initial energy. If the membrane fluctuation decreased the energy, the trial fluctuation is accepted and the procedure is reiterated starting from the new membrane configuration. To the contrary, if the membrane energy increased with the trial fluctuation, the latter may be rejected with some probability depending on the configuration's energy difference. In this case, a new fluctuation is attempted from the initial configuration. Between trial fluctuations, the cell-membrane vertices are examined. For the active zipper, the vertices within the closed neighborhood of the particle are immobilized for the remainder of the simulation. For the passive zipper, every membrane fluctuation may be reversed at a later time.

\section{Additional simulation parameters}

(1) The amplitude of a membrane fluctuation. This parameter is set to $0.5 R_{0}$ in all the simulations. (2) The mesh size, describing the maximal distance between two neighboring vertices. This parameter is set to $R_{0}$. (3) Minimal width of a membrane fluctuation. To ensure that a minimum number of vertices is involved in each fluctuation, this parameter is set to $4 R_{0}$. (4) Mesh refinement range. Our simulation script automatically refines the mesh locally around a previously immobilized vertex within this range. This parameter is set to the particle radius $R$, leading to reasonably smooth cup shapes in a reasonably short calculation time (1-2 days for complete uptake using a Intel(R) Core(TM)2 Quad $\mathrm{CPU}$ working at $2.50 \mathrm{GHz}$ and run by the RedHat EL5 linux distribution with 4 GB RAM).

\section{Experimental techniques Cells, plasmids and antibodies}

COS-7 fibroblast cells were obtained from American Type Culture Collection (ATCC) and cultured in Dulbecco's Modified Eagle's Medium (DMEM), supplemented with $10 \%$ foetal bovine serum (FBS) and penicillin/ streptomycin (Invitrogen). cDNAs encoding wild-type and Y282F/Y298F human Fc $\gamma$ RIIa from pRK5-Fc $\gamma$ RIIa [87] and pRK5-Y282F/Y298F-Fc $\gamma R I I a$ [88] were subcloned into pEGFP-N1 (Clontech) using primers 5'ggtccaactgcacctcggt-3' and 5 '-cccccgaattctgttattact gttgacatggtc-3'. The cytoplasmic tail truncation mutant 239-Fc $\gamma$ RIIa was generated from the pRK5-Fc $\gamma$ RIIa template using primers 5'-ggtccaactgcacctcggt-3' and 5'gggggggaattctcctgcagtagatcaagg ccact-3'. Rabbit antibovine serum albumin (BSA) serum was purchased from Sigma-Aldrich. Alexa-conjugated secondary antibodies and phalloidin were purchased from Invitrogen.

\section{Transfection and phagocytic challenge}

COS-7 cells were transfected with GFP-tagged Fc $\gamma$ RIIa constructs using an Amaxa Nucleofector and Nucleofector cell line kit $\mathrm{R}$ following the manufacturer instructions. For phagocytosis assays, transfected cells were seeded onto glass coverslips in 24-well plates at a density of 15,000 cells/coverslip and incubated at $37^{\circ} \mathrm{C}$ for 72 h. 1 hour before commencement of phagocytosis assays, cells were incubated for 1 hour at $37^{\circ} \mathrm{C}$ with serum-free DMEM plus $10 \mathrm{mM}$ Hepes (Invitrogen). $1.5 \mu \mathrm{m}$ - and $3 \mu \mathrm{m}$-radius latex-polystyrene particles (Sigma-Aldrich) were opsonized by first incubating overnight at $4^{\circ} \mathrm{C}$ with $3 \%$ BSA fraction V in PBS (SigmaAldrich) followed by incubation with 1:100 dilution of rabbit anti-BSA in PBS for 1 hour at room temperature. Particles were re-suspended in ice-cold serum-free DMEM plus $10 \mathrm{mM}$ Hepes at a concentration of $1.5 \times$ $10^{6}$ particles $/ \mathrm{ml}$ and $500 \mu \mathrm{l}$ added to each coverslip. Plates were incubated on ice for 10 minutes to allow binding of particles. Medium was then replaced with pre-warmed serum-free DMEM plus $10 \mathrm{mM}$ Hepes and plates were incubated at $37^{\circ} \mathrm{C}$, then processed for scoring or microscopy as described below. Experiments carried out on cells treated with cytochalasin D were conducted as above with the addition of a 20 min preincubation step with $0.2 \mu \mathrm{M}$ cytochalasin D in serumfree DMEM plus $10 \mathrm{mM}$ Hepes at $37^{\circ} \mathrm{C}$ immediately before incubation of cells with opsonized particles. This concentration of cytochalasin D was included in all further incubation steps.

\section{Imaging of phagocytic cups}

Plates were placed on ice after a 20 minute incubation at $37^{\circ} \mathrm{C}$ and medium replaced with a 1:500 dilution of anti-rabbit Alexa 488 in $3 \%$ BSA/PBS at $4^{\circ} \mathrm{C}$ for $5 \mathrm{~min}$. Cells were fixed after incubation at $37^{\circ} \mathrm{C}$ for the 
appropriate amount of time with ice-cold $4 \%$ paraformaldehyde/PBS, permeabilised and labelled with goat anti-rabbit Alexa 633, and phalloidin Alexa 555 for visualizing $\mathrm{F}$-actin at room temperature for $30 \mathrm{~min}$. Z-series image stacks were acquired on a Zeiss LSM510 confocal microscope using a step size of $0.4 \mu \mathrm{m}$.

\section{Image analysis of phagocytic cups}

Two fluorescence channels (IgG, Fc $\gamma$ R-GFP) were acquired and analyzed using MATLAB (MathWorks). During the acquisition process, the Fc $\gamma$ R-GFP fluorescence intensity was set to zero at any pixel where the IgG intensity is null. The fluorescence intensity distribution of IgG was used to determine the coordinates of the centers of particles with their corresponding radii, using an automated search based on the Hough transform [89], available online at http://www.mathworks. com/matlabcentral/fileexchange/4985 within each 2D image. The percentage of engulfed particle surface area was calculated by comparing the local FcyR-GFP (cell membrane) and IgG (particle surface) intensity distributions within a sphere $S_{0}$ of radius $4 R / 3$ whose center coincides with the particle center. Two methods were used to quantify the variability of the cups. The method used in the main text cuts the three-dimensional image (and hence the circular projections of particles within each imaging plane) in twenty-four angular segments, and finds the highest plane in which Fc $\gamma$ R-GFP fluorescence intensity is detected in the immediate neighborhood of the particle for each segment (see Figure 4). This analysis produces a distribution of membrane height versus angular segment index, for which we compute the average and the mean-square deviation. The average height reached by cell membrane is roughly proportional to the surface engulfed (see Additional file 1, Figure S10), and the mean-square deviation divided by the square root of the average height quantifies the variability of the phagocytic cup, excluding a trivial size dependence on the variability. The less accurate alternative method determines the angular distribution of Fc $\gamma$ R-GFP fluorescence intensity within the particle's equator plane in the particle's immediate neighborhood, keeping only particles whose uptake level comprises between 30 and $70 \%$ (roughly half-engulfed particles). Specifically, this region is cut into twenty-four identical angular segments, for which the total Fc $\gamma \mathrm{R}$ fluorescence intensity is calculated. Then the average intensity per segment is calculated, as well as the standard deviation. The higher the standard deviation, the more variable the cup.

\section{Accession Numbers}

The Fc $\gamma$ RIIa receptor is referenced in protein database Genbank http://www.ncbi.nlm.nih.gov/Genbank under the accession number CAA01563. Signaling-dead mutant receptor Y282F/Y298F-Fc $\gamma$ RIIa is obtained by replacing tyrosines $(\mathrm{Y})$ with phenylalanines $(\mathrm{F})$ at positions 282 and 298.

\section{Additional material}

Additional file 1: Supplementary information. The supplementary information file contains additional discussion on parameter values in simulations, as well as additional simulation results and fluorescence images analysis. It includes 10 supplementary figures, each accompanied by a short descriptive paragraph.

Additional file 2: Simulation movie. This file shows a 3D simulation of phagocytic engulfment.

\section{Acknowledgements}

This paper is dedicated to the memory of Emmanuelle Caron, who tragically passed away in 2009. We acknowledge Micah Dembo and Günther Gerisch for helpful discussions, and Ken Brakke for help with the Surface Evolver software. We thank Vania Braga, Tony Magee and Brian Robertson for careful reading of the manuscript, and Suhail Islam for computational support. All authors would like to acknowledge funding from the Center for Integrative Systems Biology at Imperial College (CISBIC). RGE was additionally supported by the Biotechnology and Biological Sciences Research Council grant BB/ G000131/1.

\section{Author details}

${ }^{1}$ Division of Molecular Biosciences, South Kensington Campus, Imperial College London, SW72AZ London, UK. ${ }^{2}$ Centre for Integrative Systems Biology at Imperial College (CISBIC), South Kensington Campus, Imperial College London, SW72AZ London, UK. ${ }^{3}$ Division of Cell and Molecular Biology, South Kensington Campus, Imperial College London, SW72AZ London, UK

\section{Authors' contributions}

ST participated to the conception of the model, and designed the simulation and image analysis algorithms. He carried out the simulations, image analysis, and statistical analysis of data as well as drafted the manuscript. AD and GT carried out the fluorescence imaging experiments and participated in writing the manuscript. RGE participated to the conception of the model and the interpretation of both theoretical and experimental results, and contributed to the writing of the manuscript. All authors read and approved the final manuscript.

Received: 7 July 2010 Accepted: 8 November 2010

Published: 8 November 2010

\section{References}

1. Swanson JA, Hoppe AD: The coordination of signaling during Fc receptor-mediated phagocytosis. J Leucoc Biol 2004, 76:1093-1103.

2. Swanson JA: Shaping cups into phagosomes and macropinosomes. Nat Rev Mol Cell Biol 2008, 9:639-649.

3. Underhill DM, Ozinsky A: Phagocytosis of microbes: complexity in action. Ann Rev Immunol 2002, 20:825-852.

4. Bretschneider T, Anderson K, Ecke M, Müller-Taubenberger A, SchrothDiez B, Ishikawa-Ankerhold HC, Gerisch G: The three-dimensional dynamics of actin waves, a model of cytoskeletal self-organization. Biophys J 2009, 96:2888-2900.

5. Conner SD, Schmid SL: Regulated portals of entry into the cell. Nature 2008, 422:37-44.

6. Greenberg S, Grinstein S: Phagocytosis and innate immunity. Curr Opin Immunol 2002, 14:136-145.

7. Dupuy AG, Caron E: Integrin-dependent phagocytosis: spreading from microadhesion to new concepts. J Cell Sci 2008, 121:1773-1783.

8. Groves A, Dart AE, Covarelli V, Caron E: Molecular mechanisms of phagocytic uptake in mammalian cells. Cell Mol Life Sci 2008, 65:1957-1976. 
9. Goldstein B, Faeder JR, Hlavacek WS, Blinov ML, Redondo A, Wofsy C: Modeling of early signaling events mediated by Fc区RI. Mol Immunol 2001, 38:1213-1219.

10. Castellano F, Chavrier P, Caron E: Actin dynamics during phagocytosis. Semin Immunol 2001, 13:347-355.

11. May RC, Machesky LM: Phagocytosis and the actin cytoskeleton. J Cell Sci 2001, 114:1061-1077

12. Silva E, Au-Yeung HW, Van Goethem E, Burden J, Franc NC: Requirement for a Drosophila E3-ubiquitin ligase in phagocytosis of apoptotic cells. Immunity 2007, 27:585-596.

13. Yu X, LU N, Zhou Z: Phagocytic receptor CED-1 initiates a signaling pathway for degrading engulfed apoptotic cells. PLoS Biol 2008, 6:e61.

14. Kinchen JM, Ravichandran KS: Phagosome maturation: going though the acid test. Nature Rev Mol Cell Biol 2008, 9:781-795.

15. Hampton MB, Kettle AJ, Winterbourn CC: Inside the neutrophil phagosome: oxidants, myeloperoxidase, and bacterial killing. Blood 1998, 92:3007-3017.

16. Segal AW: How neutrophils kill microbes. Ann Rev Immunol 2005 , 23:197-223.

17. Kraft S, Kinet JP: New developments in Fc囚RI regulation, function and inhibition. Nature Rev Immunol 2007, 7:365-378.

18. Daëron M: Fc receptor biology. Ann Rev Immunol 1997, 15:203-234.

19. Tohyama $\mathrm{Y}$, Yamamura $\mathrm{H}$ : Complement-mediated phagocytosis: the role of Syk. IUBMB life 2008, 58:304-308.

20. Champion JA, Mitragotri S: Role of target geometry in phagocytosis. Proc Natl Acad Sci USA 2006, 103:4930-4934.

21. Niedergang F, Colucci-Guyon E, Dubois T, Raposo G, Chavrier P: ADP ribosylation factor 6 is activated and controls membrane delivery during phagocytosis in macrophages. J Cell Biol 2003, 161:1143-1150.

22. Allen LA, Aderem A: Molecular definition of distinct cytoskeletal structures involved in complement- and Fc receptor-mediated phagocytosis in macrophages. J Exp Med 1996, 184:627-637.

23. Le Cabec V, Carreno S, Moisand A, Bordier C, Maridonneau-Parini I: Complement Receptor 3 (CD11b/CD18) Mediates Type I and Type II Phagocytosis During Nonopsonic and Opsonic Phagocytosis, Respectively. J Immunol 2002, 169:2003-2009.

24. Chan C, Beltzner CC, Pollard TD: Cofilin dissociates Arp2/3 complex and branches from actin filaments. Curr Biol 2009, 19:537-545.

25. Colombelli J, Besser A, Kress H, Reynaud EG, Girard P, Caussinus E, Haselmann U, Small JV, Schwarz US, Stelzer EHK: Mechanosensing in actin stress fibers revealed by a close correlation between force and protein localization. J Cell Sci 2009, 122:1665-1679.

26. Charras GT, Hu CK, Coughlin M, Mitchison TJ: Reassembly of contractile actin cortex in cell blebs. J Cell Biol 2006, 175:477-490.

27. Svitkina T, Borisy GG: Arp $2 / 3$ complex and actin depolymerizing factor/ cofilin in dendritic organization and treadmilling of actin filament array in lamellipodia. J Cell Biol 1999, 145:1009-1026.

28. Medalia O, Beck M, Ecke M, Weber I, Neujahr R, Baumeister W, Gerisch G: Organization of actin networks in intact filopodia. Curr Biol 2007, 17:79-84.

29. Yin $\mathrm{HL}$, Albrecht $\mathrm{JH}$, Fattoum A: Identification of gelsolin, a $\mathrm{Ca}^{2}$ ${ }^{+}$-dependent regulatory protein of actin gel-sol transformation, and its intracellular distribution in a variety of cells and tissues. J Cell Biol 1981, 91:901-906.

30. Arora PD, Chan MW, Anderson RA, Janmey PA, McCulloch CA: Separate functions of gelsolin mediate sequential steps of collagen phagocytosis. Mol Biol Cell 2005, 16:5175-5190.

31. Serrander L, Skarman P, Rasmussen B, Witke W, Lew DP, Krause KH, Stendhal O, Nusse O: Selective inhibition of IgG-mediated phagocytosis in gelsoline-deficient murine neutrophils. J Immunol 2000, 165:2451-2457.

32. Boulais J, Trost M, Landry C, Dieckmann R, Levy E, Soldati T, Michnick S, Thibault P, Desjardins M: Evolutionary adaptation of phagocytosis modeled the adaptive immune system. Immunity 2010.

33. Holevinski KO, Nelson DJ: Membrane capacitance changes associated with particle uptake during phagocytosis in macrophages. Biophys J 1998, 75:2577-2586.

34. Cannon GJ, Swanson JA: The macrophage capacity for phagocytosis. $J$ Cell Sci 1992, 101:907-913.

35. Niedergang F, Chavrier P: Signaling and membrane dynamics during phagocytosis: many roads lead to the phagos(R)ome. Curr Opin Cell Biol 2004, 16:422-428.
36. Hallett MB, Dewitt S: Ironing out the wrinkles of neutrophil phagocytosis. Trends Cell Biol 2007, 17:209-214.

37. Herant M, Heinrich V, Dembo M: Mechanics of neutrophils phagocytosis: behavior of the cortical tension. J Cell Sci 2005, 118:1789-1797.

38. Champion JA, Mitragotri S: Shape induced inhibition of phagocytosis of polymer particles. Pharm Res 2009, 26:244-249.

39. Van Zon JS, Tzircotis G, Caron E, Howard M: A mechanical bottleneck explains the variation in cup growth during FcyR phagocytosis. Mol Sys Biol 2009, 5:298.

40. Griffin FM, Griffin JA, Leider JE, Silverstein SC: Studies on the mechanism of phagocytosis. J Exp Med 1975, 142:1263-1282.

41. Griffin FM, Griffin JA, Leider JE, Silverstein SC: Studies on the mechanism of phagocytosis. II. The interaction of macrophages with antiimmunoglobulin lgG-coated bone marrow-derived lymphocytes. J Exp Med 1976, 144:788-809.

42. Herant $M$, Heinrich $V$, Dembo M: Mechanics of neutrophils phagocytosis: experiments and quantitative models. J Cell Sci 2006, 119:1903-1913.

43. Decuzzi $P$, Ferrari M: The role of non-specific interactions in receptormediated endocytosis of nanoparticles. Biomaterials 2007, 28:2915-2922.

44. Decuzzi P, Ferrari M: The receptor-mediated endocytosis of nonspherical particles. Biophys J 2008, 94:3790-3797.

45. Gao H, Shi W, Freund LB: Mechanics of receptor-mediated endocytosis. Proc Natl Acad Sci USA 2005, 102:9464-9474.

46. Snijder B, Sacher R, Rämö P, Damm EM, Liberali P, Pelkmans L: Population context determines cell-to-cell variability in endocytosis and virus infection. Nature 2009, 461:520-523.

47. Corbett-Nelson EF, Mason D, Marshall JG, Collette Y, Grinstein S: Signalingdependent immobilization of acylated proteins in the inner monolayer of the plasma membrane. J Cell Biol 2006, 174:255-265.

48. Ananthakrishnan R, Ehrlicher A: The forces behind cell movement. Int $J$ Biol Sci 2007, 3:303-317.

49. Mogilner A, Oster G: Cell motility driven by actin polymerization. Biophys J 1996, 71:3030-3045

50. Mogilner A, Oster G: Force generation by actin polymerization II; the elastic ratchet and tethered filaments. Biophys J 2003, 84:1591-1605.

51. Mitchell MA, Huang MM, Chien P, Indik ZK, Pan XQ, Schreiber AD: Substitutions and deletions in the cytoplasmic domain of the phagocytic receptor FcyRIIA: effect on receptor tyrosine phosphorylation and phagocytosis. Blood 1994, 84:1753-1759.

52. Odin JA, Edberg JC, Painter CJ, Kimberly RP, Unkeless JC: Regulation of phagocytosis and $\left[\mathrm{Ca}^{2+}\right]$ flux by distinct regions of an Fc receptor. Science 1991, 254:1785-1788.

53. Andrews NL, Lidke KA, Pfeiffer JR, Burns AR, Wilson BS, Oliver JM, Lidke DS: Actin restricts $\mathrm{FczRI}$ diffusion and facilitates antigen-induced receptor immobilization. Nature Cell Biol 2008, 10:955-963.

54. Ji L, Lim J, Danuser G: Fluctuations of intracellular forces during cell protrusion. Nature Cell Biol 2008, 10:1393.

55. Helfrich W: Elastic properties of lipid bilayers: theory and possible experiments. Z Naturforsch [C] 1973, 28:693-703.

56. Dieckmann R, Von Heyden Y, Kistler C, Gopaldass N, Hausherr $S$ Crawley SW, Schwarz EC, Diensthuber RP, Cote GP, Tsiavaliaris G, Soldati T: A Myosin IK-Abp1-PakB circuit acts as a switch to regulate phagocytosis efficiency. Mol Biol Cell 2010, 21:1505-1518.

57. Hagedorn M, Rohde KH, Russell DG, Soldati T: Infection by tubercular mycobacteria is spread by nonlytic ejection from their amoeba hosts. Science 2009, 323:1729-1733.

58. Rosenberger CM, Finlay BB: Phagocyte sabotage: disruption of macrophage signalling by bacterial pathogens. Nat Rev Mol Cell Biol 2003, 4:385-396.

59. Cornelis GR: The Yersinia Ysc-Yop 'Type III' weaponry. Nat Rev Mol Cell Biol 2002, 3:742-754.

60. Muttil P, Wang C, Hickey AJ: Inhaled drug delivery for tuberculosis therapy. Pharm Res 2009, 26:2401-2416.

61. Charras GT, Yarrow JC, Horton MA, Mahadevan L, Mitchison TJ: Nonequilibration of hydrostatic pressure in blebbing cells. Nature 2005, 435:365-369.

62. Huang $H$, Sylvan J, Jonas M, Barresi R, So PTC, Campbell KP, Lee RT: Cell stiffness and receptors: evidence for cytoskeletal subnetworks. Am J Physiol Cell Physiol 2005, 288:C72-C80.

63. Roduit C, Van der Goot FG, Los Rios P, Yersin A, Steiner P, Dietler G, Catsicas S, Lafont F, Kasas S: Elastic membrane heterogeneity of living 
cells revealed by stiff nanoscale membrane domains. Biophys $J$ 2008, 94:1521-1532.

64. Raucher D, Sheetz MP: Characteristics of a membrane reservoir buffering membrane tension. Biophys J 1999, 177:1992-2002.

65. Raucher D, Sheetz MP: Membrane expansion increases endocytosis rate mitosis. J Cell Biol 1999, 144:497-506.

66. Sobota A, Strzelecka-Kiliszek A, Gladkowska A, Yoshida K, Mrozinska K, Kwiatkowska $\mathrm{K}$ : Binding of $\operatorname{lgG}$-opsonized particles to $\mathrm{Fc \gamma R}$ is an active stage of phagocytosis that involves receptor clustering and phosphorylation. J Immunol 2005, 175:4450-4457.

67. Kress H, Stelzer EHK, Holzer D, Buss F, Griffiths G, Rohrbach A: Filopodia act as phagocytic tentacles and pull with discrete steps and a loaddependent velocity. Proc Natl Acad Sci USA 2007, 104:11633-11638.

68. Swanson JA, Johnson MT, Beningo K, Post P, Mooseker M, Araki N: A contractile activity that closes phagosomes in macrophages. J Cell Sci 1999, 112:307-316

69. Clarke M, Müller-Taubenberger A, Anderson KI, Engel U, Gerisch G: Mechanically induced actin-mediated rocketing of phagosomes. Mol Biol Cell 2006, 17:4866-4875.

70. Broder D, Pogliano K: Forespore engulfment mediated by a ratchet-like mechanism. Cell 2006, 126:917-928.

71. Cowman AF, Crabb BS: Invasion of red blood cells by malaria parasites. Cell 2006, 124:755-766.

72. Brown FLH: Elastic modeling of biomembranes and lipid bilayers. Ann Rev Phys Chem 2008, 59:685-712.

73. Brakke K: The surface evolver. Exp Math 1990, 1:41.

74. Zhelev DV, Needham D, Hochmuth RM: Role of the membrane cortex in neutrophil deformation in small pipets. Biophys J 1994, 67:696-705.

75. Gordon AH, D'Arcy Hart P, Young MR: Ammonia inhibits phagosomelysosome fusion in macrophages. Nature 1999, 286:79-80.

76. Greenberg S: Modular components of phagocytosis. J Leukoc Biol 1999, 66:712-717.

77. Tardieu I, Webster P, Ravesloot J, Boron W, Lunn JA, Heuser JE, Andrews NW: Lysosome recruitment and fusion are early events required for trypanosome invasion of mammalian cells. Cell 1992, 71:1117-1130.

78. Keown MB, Henry AJ, Ghirlando R, Sutton BJ, Gould HJ: Thermodynamics of the interaction of human immunoglobulin $E$ with its high affinity receptor FceRI. Biochemistry 1998, 37:8863-8869.

79. Phillips DJ, Wells TW, Reimer CB: Estimation of association constants of 42 monoclonal antibodies to human IgG epitopes using a fluorescent sequential-saturation assay. Immunol Lett 1987, 17:159-168.

80. Raychaudhuri G, McCool D, Painter RH: Human IgG1 and its Fc fragment bind with different affinities to the Fc receptors on the U937, HL-60, and ML-1 cell lines. Mol Immunol 1985, 22:1009-1019.

81. Wallace PK, Keler T, Coleman K, Fisher J, Vitale L, Graziano RF, Guyre PM, Fanger MW: Humanized mAb $\mathrm{H} 22$ binds the human high affinity Fc receptor for $\lg \mathrm{G}(\mathrm{F} c \gamma \mathrm{RI})$, blocks phagocytosis, and modulates receptor expression. J Leukoc Biol 1997, 62:469-479

82. Gandour DM, Walker WS: Macrophage cell cycling: influence on Fc receptors and antibody-dependent phagocytosis. J Immunol 1983, 130:1008-1012.

83. Moseley JB, Mayeux A, Paoletti A, Nurse P: A spatial gradient coordinates cell size and mitotic entry in fission yeast. Nature 2009, 459:857-860.

84. Tzur A, Kafri R, LeBleu VS, Lahav G, Kirschner MW: Cell Growth and Size Homeostasis in Proliferating Animal Cells. Science 2009, 325:167-171.

85. Metropolis N, Rosenbluth AW, Rosenbluth MN, Teller AH, Teller E: Equations of State Calculations by Fast Computing Machines. J Chem Phys 1953, 21:1087-1092.

86. Piotto S, Mavelli F: Monte Carlo simulations of vesicles and fluid membranes transformations. Ori Life Evo Bios 2004, 34:225-235.

87. Caron E, Hall A: Identification of two distinct mechanisms of phagocytosis controlled by different Rho GTPases. Science 1998, 282:1717.

88. Cougoule C, Hoshino S, Dart A, Lim J, Caron E: Dissociation of recruitment and activation of the small G-protein Rac during Fcy receptor-mediated phagocytosis. J Biol Chem 2006, 281:8756-8764.

89. Ballard DH: Generalizing the Hough transform to detect arbitrary shapes. Pattern Recogn 1981, 13:2.

doi:10.1186/1752-0509-4-149

Cite this article as: Tollis et al.: The zipper mechanism in phagocytosis: energetic requirements and variability in phagocytic cup shape. $B M C$ Systems Biology 2010 4:149.

\section{Submit your next manuscript to BioMed Central and take full advantage of:}

- Convenient online submission

- Thorough peer review

- No space constraints or color figure charges

- Immediate publication on acceptance

- Inclusion in PubMed, CAS, Scopus and Google Scholar

- Research which is freely available for redistribution

Submit your manuscript at www.biomedcentral.com/submit 